\title{
Perceived Time Available: The Margin of Safety in Fires
}

\author{
JONATHAN D. SIME \\ School of Architecture \\ Portsmouth Polytechnic, United Kingdom
}

\section{ABSTRACT}

The knowledge people have of the degree of fire threat is considered to be important to an understanding of the time people need for response. 'Time needed' is a psychological concept which varies in terms of the 'perceived' time available (PTA) to carry out various actions. A distinction is made between the objective and subjective (perceived) availability of escape (or refuge) options: termed ODF and SDF 'Degrees of Freedom'. Analyses are presented of the time lag between the fire growth (ODF) and a person's knowledge of the degree of threat (SDF), also the diminishing availability of escape routes. The time components of different 'Required Safe Egress Time' equations are discussed. An alternative equation is discussed. Two integrated levels of analysis are necessary in monitoring the timing of people's actions in fires (A) the psychological/ social goal of the action: (B) the location of the action as a person moves around a building. Attempts to measure the duration of behaviour are discussed together with recommendations for future research. It is suggested that PTA should feature in any calculations of margins of safety in equations contrasting time needed and time available.

\section{INTRODUCTION}

Fire tragedies involving a large number of fatalities usually have one simple feature in common. A serious delay occurred in the occupants of the building becoming or being made aware of the encroaching danger. In the Summerland Fire, Isle of Man, U.K. 1973 (in which 50 people died) and the Beverly Hills Supper Club Fire, U.S.A. 1977 (in which 164 died), there was some 20 minutes from the time of the initial discovery of the fire by a staff member to the point when most people became fully aware of a direct danger to their lives. What had been sufficient time available for egress turned into a situation in which the time needed for everyone to leave was too great to guarantee their safety. In this respect the concepts of time 'needed' (or 'required') and time available for egress, juxtaposed in safety planning and design formulae, could be usefully complemented by attention to the time available as perceived by people in fires. This concept of perceived time available (PTA) is a central focus of this paper and helps in understanding patterns of movement preceding any attempt to escape.

Acknowledgement: Several analyses presented in this paper were carried out by my former colleague in the Fire Research Unit, University of Surrey: Dr. John Breaux. I would like to acknowledge his contribution. 
The aim of the paper is to shift the focus away from measures of time needed which concentrate almost exclusively on egress. For important time can be lost in the period preceding egress. Thinking of the perceived time available (PTA) highlights the incomplete knowledge about the fire threat people in different parts of a building are likely to have at different stages. PTA refers to the time an individual feels is available, for example, to reach an exit and knowledge of the time available to carry out the action. PTA can also refer to a person's view of the likelihood that other people will be able to carry out an action in time to avoid injury. People in fires often pursue investigative and affiliative actions (moving towards other people) in an attempt to reduce uncertainty. The amount of information about a fire influences the timing of people's escape and effectiveness of their actions.

\section{OBJECTIVE AND SUBJECTIVE DEGREES OF FREEDOM}

Ficure 1 is a representation of the rate of fire growth in relation to the diminishing availability of escape or refuge options in a hotel fire. The options, termed objective and objective (perceived) 'degrees of freedom' by Breaux (1), diminished rapidly once a fire took hold. As he points out "The unfortunate aspect is that once a fire reaches the stage of giving off noises, it is approaching or has reached the stage when one can expect nonlinear growth".

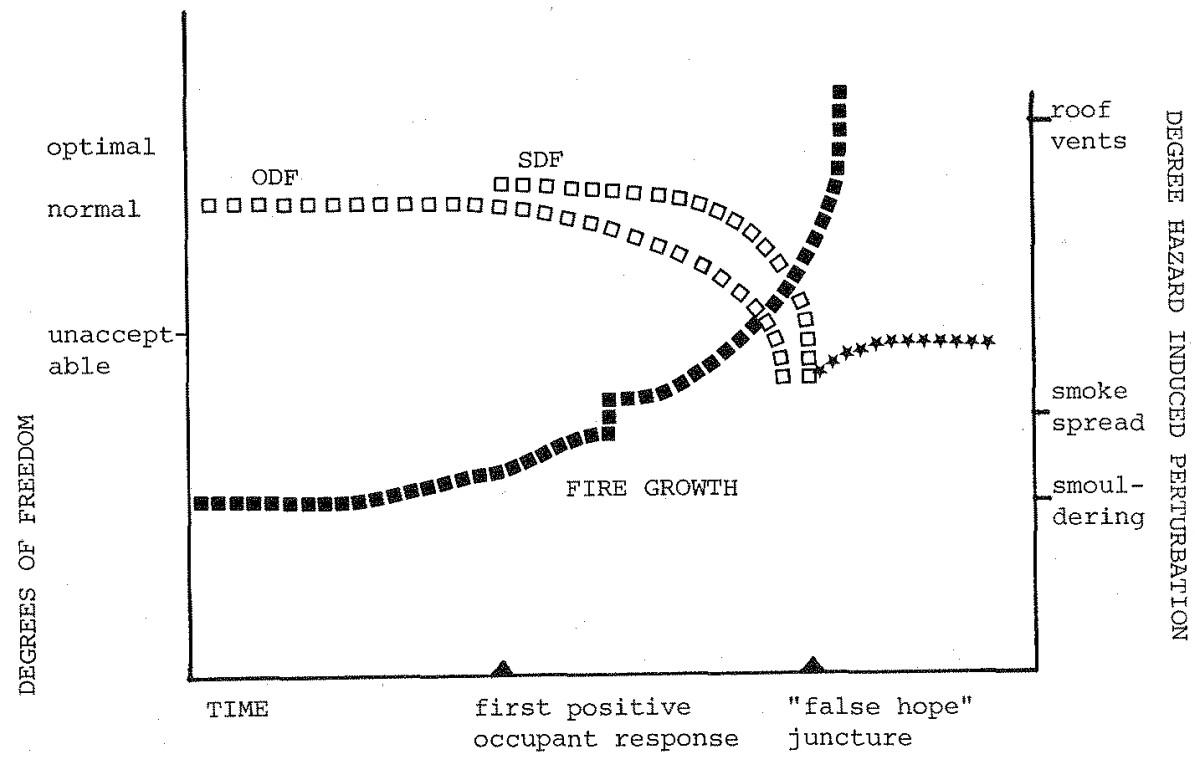

Figure 1: from Breaux (1) Dependency of ODF (Objective Degree of Freedom) and SDF (Perceived Degree of Freedom) on growth of fire for "Unsuccessful" occupants. 
Although we were not able to measure the durations of actions in this fire our attempts in general to carry out statistical analyses on act sequences in fires $(2,3,4)$ have explored the temporal sequence of acts. In another study of the hotel fire represented in Figure 1, I traced (mapped out) the

path and distance of movement on the architectural plan of the building (3). The sources of data were interview transcripts from the 33 fire survivors. The fire was chararacterised not only by guests in the hotel not being aware of the fire spreading up the central staircase until it was too late to leave by a 'normal route', but the misinterpretation of early cues to the fire's existence.

Movement by the hotel occupants generally involved individuals opening their hotel room door to investigate noises, only to find the fire had already cut off the main stairway route to safety. The fire began sometime before $2.00 \mathrm{am}$. It is estimated by the fire brigade, who arrived at 2.11 am, that within six minutes of the fire being first discovered by one of the residents it had involved the central stairway enclosure.

The 'time lag' between the objective growth of a fire and people's knowledge of this and available escape routes from different parts of a building is characteristic of many serious fires. In fires we studied ranging from domestic fires in buildings of one or two storeys, to large-scale multipleoccupancy fires, the early stage of recognition was often characterised by ambiguous information cues. In a number of cases there was a serious delay in people taking these cues seriously before they realised there was a fire. Unknown to the occupants the fire was already reducing the time avajlable to reach safety.

A further analysis (2) showed that the likelihood of reaching safety without assistance in the hotel fire example depended on accurately interpreting the early ambiguous cues. Breaux describes the 'false hope juncture' along the abscissa of Figure 1 as, "a situation for several individuals in which the ability to evade the fire was so curtailed that they were considering jumping from a fourth floor window". In this case, the respondents subjective degrees of freedom (i.e. alternatives considered viable) appear to have changed to admit an option previousiy not entertained.

Figure 2 represents an analysis by Breaux (2) of escape reduction as a function of time for the hotel fire together with data recorded for the Beverly Hills Supper Club Fire $(5,6)$. Both events share a similar time scale. Point $A$ represents the 'design potential' for the English structure and those rooms in the American nightclub. As Breaux points out "ironically, by mere virtue that people are using the buildings there is already a reduction in possible escape routes. This is due to such measures as locking doors to keep out pilferers, gatecrashers and others for whom entry is unauthorised. This in itself is interesting for it means that certain structures are already affected before the fire"

In both cases the fire begins somewhat after $B$ in Figure 2. As Breaux points out "In total, the curve which describes progressive route reduction is of a history or sigmoid type. Of primary interest concerning the fire is that section defined by the function $Y=a x^{b}$ which extends from ' $B$ ' onwards. The meaning of this environmental relationship is, simply, ways to escape disappear at an ever faster rate". 


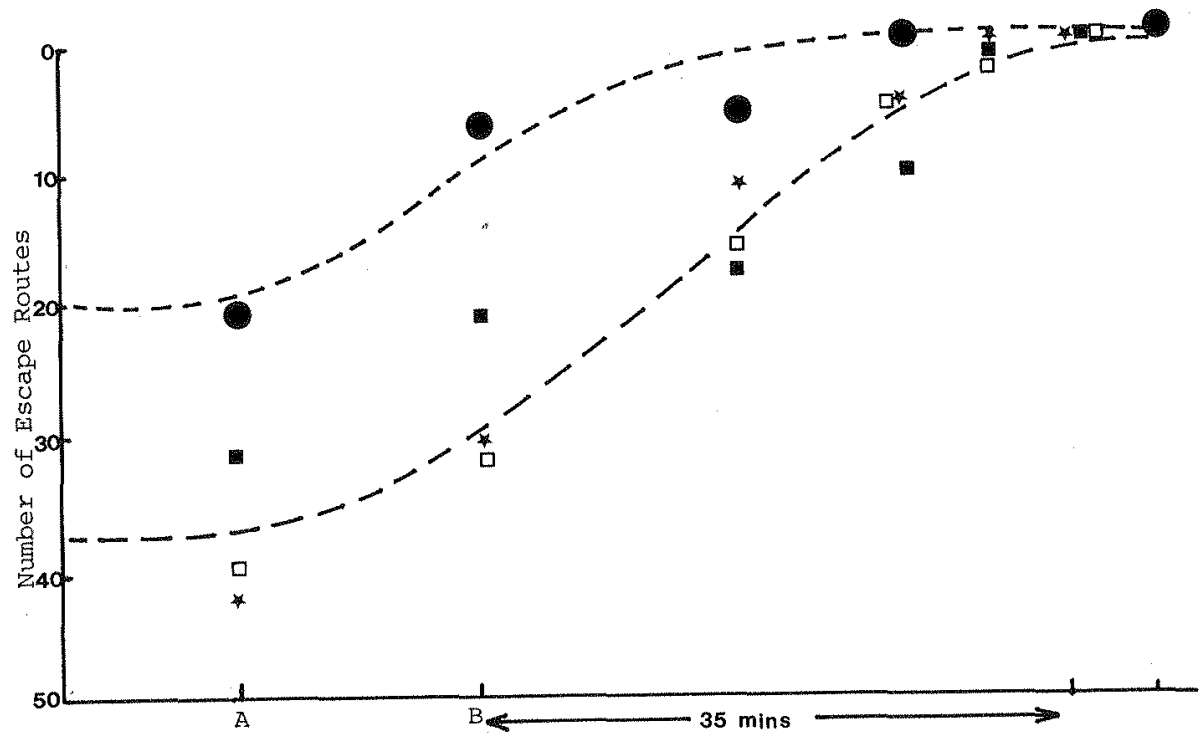

Figure 2: from Breaux (2) Escape route reduction as a function of time. Areas indicated are Cabaret Room * Empire Room, and Kitchen a (data from Best, (5). English hotel fire data $O$. Design potential and pre-fire status indicated by $A$ and $B$ respectively.

The behaviour of people, the escape route capacity, the fire growth are interrelated. This is best illustrated by the fact that the main reason for a rapid change in the escape possibilities of people is often the point when a person investigating a source of ambiguous information opens a door to the room of fire origin. Either the person forgets to close the door or is often unable to as the fire, which has been developing for some time in an enclosed space, rapidly escapes into the building from where the person has come. Time needed expands or reduces by virtue of a person's knowledge of the threat (i.e. perceived time available: PTA).

\section{STAGES IN REQUIRED SAFE EGRESS TIME}

The terms 'time needed' and 'time available' derive directly from recent attempts to 'model' what is going on in fires. A number of people have elaborated an equation for estimating life safety, in which the basic principle adhered to is that the time it takes for an individual or building population to reach safety, should not exceed the time it takes for fire conditions to make it possible to reach safety. The simplest form of this time needed versus

time available equation (7) is:

$\frac{\text { Te }}{\text { Tc }}<1$

Equation (a)

where $\mathrm{Te}=$ Time required for escape

$T c=$ Time required for the toxic environment to reach a critical or untenable state 
Under the heading of 'escape route analysis' Marchant (8) presented an equation which breaks down the 'time required' into 3 components:

$\frac{T p+T a+T r s}{T f} \leqslant 1 \quad$ Equation (b)

where $T p=$ Elapsed time from ignition to perceive that a fire exists $T a=$ Elapsed time from perception to the beginning of safety action Trs = Elapsed time from initiation of safety action to reach a place of safety

Tf = Elapsed time from ignition for the fire to develop untenable environmental conditions

Stah1, Crosson and Margulis (9) have broken down the 'time required' component even further, concentrating on the sensation and perception of a fire and evaluation of the degree of 1 ife threat. As Stahl et al acknowledge, their expanded form of equation (1) may be difficult to apply and estimate accurately in fires.

$\frac{T a+T s+T t+T e+T i+T x}{T c}<1$

Equation (c)

where $\mathrm{Ta}=$ Time required for sensation of a stimulus from the fire environment

Ts = Time required to become aware of this sensation

$T t=$ Time required to become aware of the sensation as a potential life threat

Te = Time required to evaluate the quality and extent of the life threat

$T i=$ Time required to initiate effective actions

$T x=$ Time required to follow-through and complete actions leading to safety

This equation (c) is clearly closer than equation (a) to the concept of perceived time available (PTA). Some confusion is possible in equations (b) and (c) in the definition of what constitutes a 'safety' or 'effective' action. As they stand, these terms could encompass certain actions prior to escape (e.g. contact fire brigade, warn others) as well as escape behaviour itself. One might assume that Ta (equation $b$ ) $=T i$ (equation $c$ ) and

Trs $(b)=T x(c)$. Without clearer definitions it is possible to make assumptions with which the authors of these equations might disagree or at least would acknowledge are open to discussion.

Cooper (10) has been working on the 'time available' aspects of a model of fire growth. The aim has been to develop a quantitative criterion for safe building design, which he terms the 'designed safety egress criterion', viz: relative to a potentially hazardous fire, a building is of safe design if

ASET $=$ Thaz - Tdet $>$ RSET

This principle expressed in the same terms as equations RSET $<1$

$\overline{\text { ASET }}$
Equation (d)

(1) to (3) gives:

Equation (d) 
where RSET = Required Safe Egress Time: the length of time subsequent to alarm which is actually required for safe occupant egress from threatened spaces

ASET = Available Safe Egress Time: the length of time interval between fire detection/alarm, Tdet and the time of onset of hazardous conditions, Thaz

Cooper concentrates on possible ways in which to estimate ASET. He writes "Assuming a capability for estimating RSET, the results of this study, through application of the designed safety egress criterion, would lead to rational evaluations of building safety." Where there is an immediate problem in this model is that it refers to egress movement following an 'alarm'.

To take account of the pattern of psychological and social responses in a variety of fires, any principle of safety design has to accommodate rather than discount the time it takes to respond to an 'alarm' or 'cue'. Unless there is a highly efficient communication system (public announcement system) people in different parts of a building are not, or cannot by definition be, simultaneously aware of the degree of a threat. The ASET model is currently addressed primarily to the issue of egress systems and forms of fire resistance designed into the building. Yet what is crucial is not only the time it takes to move to safety but when this movement begins.

\section{A REVISED RSET EQUATION}

The following equation, which concentrates on RSET, is intended to accommodate both the perceived time component and the pattern of movement prior to and during movement to safety. It is being used as the basic framework by a research team consisting of Maclennan, Pauls and Sime to develop a model of human behaviour applicable to assessing the adequacy of part 24 of the Australian Model Uniform Building Code, (a research project commissioned by the Australian Uniform Building Regulations Co-ordinating Council (12). The research involves monitoring evacuation times from office blocks (above 6 storeys in height). A definition of this model is as follows:

$\frac{T r+T c+T e}{T f}<1$

Equation (e)

where $\mathrm{Tr}=$ Recognition Phase: time from being alerted by a cue to knowing there is an emergency fire (includes acts such as investigate)

$T c=$ Coping Phase: time from knowing there is an emergency to beginning of escape (includes acts such as fight fire)

$T e=$ Escape/Evacuation phase: time from the end of the coping phase i.e. beginning escape (evacuation) to leaving the building

RSET $=T r+T c+T e$

ASET $=\operatorname{Tf}$ (as in equation b)

Two levels of definition are necessary if one is to 'model' the interrelationship between behaviour in an emergency and a building's design.

Level $(A)=$ Psychological/Social goal

(B) = Location of movement through building 
Mroom = Movement within room (before leaving through exit)

Mcorr = Movement within corridor (before leaving through exit onto stairway)

Mstair = Movement down staircase

Mgrnd = Movement on ground floor (before exiting from building)

Any reference to (1) Goal is qualified by referring to (2) Movement. Both are essential for an understanding of the temporal and spatial aspects of sequences of actions in an emergency. Unfortunately, research to date has concentrated almost exclusively on (1) or (2).

In terms of the Australian research on high-rise office buildings, the primary distinction will be between movement which takes place on the upper floor of a building and that on a protected stairway. These phases are termed:

$M H=$ Horizontal component of evacuation: movement on upper floor prior to leaving through an exit from the floor (Mroom + Mcorr)

$M V=$ Vertical component of evacuation: from entry into the protected exit system to the time of entry into open space or an approved refuge area (normally involves movement down stairway and on the floor of final access to the outside). (Mstair + Mgrnd)

The task will be to try to establish broad time estimates for these movement phases. In equation (e) RSET includes a recognition phase (Tr), and ASET a detection phase (Tdet).

Mcclennan (11) uses the term 'Exit Access' to refer both to the psychological/social factors involved in people moving towards an exit from a space and the physical design of access to an area of 'relative' or 'complete' safety. The aim here is to develop a design model which integrates research on psychological/social responses and the timing of physical movement to and through exits.

\section{MEASURING THE TIME IT TAKES TO RESPOND IN FIRES}

A recent overview of egress research in relation to the N.F.P.A.'S 1976 Life Safety Code (9) reflects limited knowledge of the time people expend in the early stages of a fire. Research on building evacuations (12) has been able to use 'time' directly as a measure of movement. Yet the time to act in the $T r$ and $T c$ stages has been ignored or inferred to date due to the problems in (a) measuring time directly in fires (b) reliability of time estimates given by fire survivors.

In one questionnaire survey (13) people were asked to estimate the time it took for them 'in leaving' buildings on fire. The average estimate of time to leave of 1.92 minutes was inevitably nearer to 'perceived' than actual time. Moreover the question of what constitutes 'leaving' is open to different interpretations since in low-rise domestic fires (a high percentage of the sample) leaving a house can take place in the Tr. Tc or Te stages and can be followed by re-entry more than once. The few time experiments which have been conducted (14)(15)(16) generally suggest it would be difficult to obtain reliable estimates from individuals of the actual distances they travel in fires. This difficulty would be reduced in research of behaviour in fires if the 'estimates' were compared with objective physical measures of the distances along routes through the building which people indicated they followed. 
Experiments on potential entrapment simulate the scramble for an exit assumed to occur when people are faced by the diminishing possibility of everyone reaching safety in a fire (17) but bear little similarity to the time it takes to reach an exit in a fire. This experimental research of RSET/ASET ignores the ambiguity of fires and delays in warning which make such behaviour so unavoidable (18).

It may well be that the greatest potential for incorporating valid time estimates into an RSET/ASET model is in the area of simulation research in which time can be measured directly. Some research has measured the time it takes to evacuate a ward (19) and to enact different sequences of actions (20) in fire role playing exercises. Recording times for the early phases of monitored evacuations (21) will yield useful information. If the behaviour is also found to occur in researched fires, it could provide a useful estimate of the likely duration of acts which otherwise could not be recorded. The validity of role playing exercises and advice, on how to decrease needed time and increase available time in emergency planning (22), depends very much on the adequacy of research on actual behaviour in emergencies. By 'mapping' distances moved by people in fires (using architectural plans) (3) it may be possible to assign estimated travel times to these distances, based on knowledge of the fires and knowledge of characteristic speeds of 'pedestrian movement'. Video disc simulations of escape routes, as potentially viewed by escapees in fires, could also incorporate a time component (23).

\section{IMPROVING THE MARGIN OF SAFETY}

What one wants to move away from is the tenous basis for time estimates enshrined in design yardsticks. For example, an assumption in the British codes is that a fire compartment should be evacuated in $2 \frac{1}{2}$ minutes if people's safety is to be assured (24). The recent fire tragedy at Bradford City Football Club (May 1985) highlights the problems in concentrating on the $2 \frac{1}{2}$ minutes escape criterion without taking into account the time to begin movement (25). This period of time may exceed $2 \frac{1}{2}$ minutes and suggests the importance of a prompt warning to evacuate being put over a public announcement system.

The reason for emphasizing PTA, as an essential component of a RSET/ASET model, was my concern to point out the danger in considering that a direct mathematical or predictive relationship can be found between time needed and time avallable, independantly of the knowledge building users have at different stages about the fire's growth. Essentially, the current problem in comparing RSET and ASET lies in the assumption that, once an automatic smoke detector or alarm is set out off, the occupants of a building recognise there is a fire and will start their escape immediately. This is rather like equating people with inanimate objects or 'snooker balls', which upon external impact from an outside physical force (the 'cue'), will be propelled towards a an exit (the 'pocket') (26). This physical-science model of people's movement assumes that $T$ det $=T r$. In contrast, there is likely to be a time lag between Tdet and Tr; thus Tdet $\neq \mathrm{Tr}$. The potential mismatch between Tdet and $\mathrm{Tr}$, the time it takes people to interpret and respond to initial changes in the social and physical environment of a fire, has to be reduced. The margin of safety, referred to in the title of this paper, is the time lag between the 'objective' and 'subjective' degrees of freedom (i.e. the actual and perceived: state of the fire and availability of exits).

In conclusion, time required is an 'elastic' psychological concept in the sense that for the people in a fire it expands or shrinks according to perceived 
time available (PTA). The characterisation of time required as a subjective concept, as well as an objective one (referring to the time it takes to move around and escape from a building), is not one with which those working on the physical fire growth and design parameters of the ASET model are likely to feel comfortable. It is, however, a more accurate reflection of the limits of knowledge of a fire threat, which explain much of people's behaviour and timing of escape in fires. The key to improving the margin of safety undoubtedly lies as much in efficient forms of information and communication about the state of the fire at different stages, as in the building's design. Time available to escape can be increased by helping people to respond promptly in the Tp (perception) phase and use the time economically in the Tc (coping) phase of response. Paradoxically, one has to try to reduce rather than increase the perceived time available, if one wants to prompt people to begin their escape in time to reach safety.

\section{REFERENCES}

1. Breaux, J.J. Analysing Complex Data: the Description and Analysis of Dynamic Behaviour in Fire Situations. Annual Conference of British Psychological Society. Exeter 31 March - 4 April, 1977.

2. Breaux, J.J. On Analysing and Interpreting Behaviour in Fires. Fire Research Unit, Psychology. Department, University of Surrey. Mimeo, 1979.

3. Sime, J.D. Escape Behaviour in Fires: 'Panic' or Affiliation ? Doctoral thesis, Psychology Department, University of Surrey (unpublished), 1984.

4. Canter, D., Breaux, J.J. and Sime, J.D. Domestic, Multiple Occupancy and Hospital Fires. In D. Canter (Ed.) Fires and Human Behaviour. Ch.8, 117-136, Chichester/New York: Wiley, 1980 .

5. Best, R.L. Investigation Report: The Beverly Hills Supper Club Fire, Southgate, Kentucky, May 28th 1977, NFPA (National Fire Protection Association) Fire Investigations Department (in co-operation with National Fire Prevention and Control Admin. and NBS (National Bureau of Standards) Draft Report, 1977.

6. Berlin, A.N. A Modelling Procedure for Analysing the Effect of Design on Emergency Escape Potential. In B.M. Levin and R.L. Paulsen (Eds.) Second International Conference on Human Behaviour in Fire Emergencies: October 29 - November 1, 1978. Proceedings of Seminar, NBS. Report NBSIR 80-2070, 13-41, Washington D.C., National Bureau of Standards, 1980.

7. Caravaty, R.D. and Haviland, D.S. Life Safety from Fire: A Guide for Housing the Elderly. Troy, N.Y.: Rensselaer Polytechnic Institute, Center for Architectural Research, 1967.

8. Marchant, E.W. Modelling Fire Safety and Risk. In D. Canter (Ed.) Fires and Human Behaviour. Chichester/New York: Wiley. Ch.16, 293-314,1982.

9. Staht, F.I., Crosson, J.J. and Margulis, S.T. Time-based Capabilities of Occupants to Escape Fires in Public Buildings: A Review of Code Provisions and Technical Literature, National Bureau of Standards, Report NBSIR 82-2480, 1982.

10. Cooper, L.Y. A Concept for Estimating Available Safe Egress Time in Fires. Fire Safety Journa 1, 5. 135-144. 
11. Maclennan, H.A. Current Research Relating Time Required and Time Available for Egress. N.F.P.A. National Fire Protection Association's Fall Meeting. San Diego, U.S.A. 12-15 November, 1984.

12. Pauls, J.L. Building Evacuation: Research Findings and Recommendations. In D. Canter (Ed.) Fires and Human Behaviour. Chichester/New York: Wiley. Ch.14, 251-276, 1980.

13. Bryan, J.L. Smoke as a Determinant of Human Behaviour in Fire Situations (Project People). Center for Fire Research, National Bureau of Standards Program for Design Concepts, Grant No.4 - 9027, 1977.

14. Langer, J. Wapner, S. and Werner, H. The Effect of Danger upon the Experience of Time. American Journal Psychology. March 74 (1), 94-97, 1961.

15. Werner, $H$. and Wapner, S. Changes in Psychological Distance under Conditions of Danger. Journal Personality, 24, 153-167, 1955.

16. Sadalla, E.K. and Magel, S.G. The Perception of Traversed Distance. Environment and Behaviour, 12 (1), 65-79, 1980.

17. Guten, S. and Vernon, L.A. Likelihood of Escape, Likelihood of Danger and Panic Behaviour. Journal of Social Psychology 87, 29-36, 1972.

18. Sime, J.D. The Outcome of Escape Behaviour in the Summerland Fire: Panic or Affiliation ? International Conference on Building Use and Safety Technology. Conference proceedings, Los Angeles 12-14 March 1985. Washington D.C: National Institute of Building Sciences (NIBS), 1985.

19. Hall, J. Patient Evacuation in Hospitals in D. Canter (Ed.) Fires and Human Behaviour. Ch.12. 205-226, Chichester/New York: Wiley, 1980.

20. Pearson, R.G. and Joost, M.G. Egress Behaviour Response Times of Handicapped and Elderly Subjects to Simulated Residential Fire Situations. National Bureau of Standards. Report NBS-GCR-83-429, 1983.

21. Sime, J.D. Post-evacuation Walkthrough (P.E.W.) Instruction Manual. New South Wales Institute of Technology, Sydney, Australia, 1985.

22. Groner, N.E. A Matter of Time - A Comprehensive Guide to Fire Emergency Planning for Board and Care Homes. National Bureau of Standards. Report NBS -GCR-82-408, 1982.

23. Sime, J.D. The Fire Game: Future Directions for Research and development. Fire Protection. February, 1985.

24. Ministry of Works Fire Grading of Buildings: Means of Escape, Part 3, Personal Safety, Post War Building Studies, 29, London, HMSO, 1952.

25. Home Office/Scottish Home and Health Department Guide to Safety at Sports Grounds (Footba11). London: HMSO (Her Majesty's Stationery Office), 1976.

26. Sime, J.D. Designing for People or Ball-bearings. Design Studies(6)3, 1985. 